\title{
Aplikasi AKO (Apoteker Keluarga Online) sebagai Media Digital Counseling dalam Upaya Penggunaan Obat yang Rasional di Masyarakat The AKO (Online Family Pharmacist) Application as a Digital Counseling Media in Efforts to Use Rational Medicines in Comunity
}

\section{Devi Ristian Octavia*, Irma Susanti}

Prodi S-1 Farmasi, Fakultas IImu Kesehatan, Universitas Muhammadiyah Lamongan, Indonesia *devioctavia1987@gmail.com
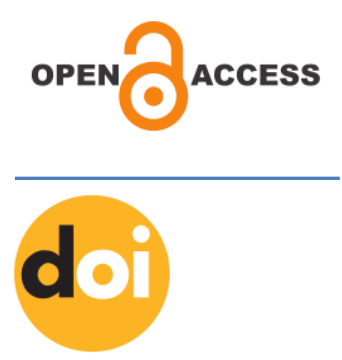

https://doi.org/10.37010 /pnd.v1i1.553

Pengabdian kepada masyarakat seharusnya berdampak bagi kemajuan ilmu dan pengetahuan. Sudah seharusnya kegiatan pengabdian kepada masyarakat dapat menginspirasi dan ditularkan kepada para dosen di Indonesia.

PUNDIMAS: Publikasi Kegiatan Abdimas adalah jurnal yang diterbitkan oleh Neolectura sebagai media publikasi kegiatan pengabdian masyarakat.

Waktu terbit: Januari, Mei, dan September di tiap tahunnya.

\begin{abstract}
Abstrak
Penduduk Indonesia telah terbiasa menggunakan bermacam jenis obat-obatan sebagai terapi terhadap penyakit, memelihara, ataupun sebagai vitamin dalam upaya menunjang kegiatan sehari-hari. Dengan banyaknya obat yang beredar secara bebas di masyarakat, maka diperlukan suatu pendekatan kepada masyarakat untuk meningkatkan awareness dan pengetahuan terhadap penggunaan obat yang rasional. Oleh karena itu, penyuluhan dalam rangka meningkatkan pengetahuan masyarakat terhadap hal tersebut sangatlah diperlukan. Pengabdian masyarakat ini dilaksanakan pada bulan November 2021 di desa Bedingin Kecamatan Sugio Kabupaten Lamongan. Sasaran atau mitra dalam pengabdian masyarakat ini adalah kader Desa Bedingin sejumlah 36 orang. Kegiatan pengabdian ini dilakukan dalam 4 tahapan mulai dari identifikasi potensi dan permasalahan mitra, penyusunan program bersama dengan masyarakat, edukasi swamedikasi rasional dan sosialisasi aplikasi AKO (Apoteker Keluarga Online) sebagai media Konsultasi Digital, Pendampingan penggunaan Obat yang Rasional dengan Media Aplikasi AKO. Hasil pengabdian didapatkan masyarakat sangat antusias dalam memanfaatkan aplikasi tersebut untuk mengonsultasikan penggunaan obatnya. Konseling secara mendalam dapat dilanjutkan dengan mengisi form konsultasi ataupun via chatting yang akan langsung dijawab oleh tim Apoteker Agent of Change yang telah dibentuk. Edukasi swamedikasi rasional dan pendampingan konsultasi penggunaan obat menggunakan aplikasi AKO mampu meningkatkan pengetahuan masyarakat tentang penggunaan obat yang rasional.
\end{abstract}

Kata Kunci: apoteker, swamedikasi, rasional

Abstract

Indonesians are accustomed to using various types of drugs as therapy for disease, maintenance, or as vitamins in an effort to support daily activities. With so many drugs circulating freely in the community, an approach to the community is needed to increase awareness and knowledge of rational drug use. Therefore, counseling in order to increase public knowledge of this is very necessary. This community service will be held in November 2021 in Bedingin Village, Sugio District, Lamongan Regency. The target or partner in this community service is the 36 Bedingin village cadres. This service activity is carried out in 4 stages starting from identifying potential partners and problems, developing joint programs with the community, rational self-medication education and socializing the AKO (Online Family Pharmacist) application as a medium for Digital Consultation, Assistance in Rational Medicine use with AKO Application Media. The results of community service obtained were very enthusiastic in using the application to consult the use of the drug. In-depth counseling can be continued by filling out a consultation form or via chat which will be immediately answered by the team of Pharmacists Agent of Change that has been formed. Rational selfmedication education and consultation assistance on drug use using the AKO application can increase public knowledge about rational drug use.

Keywords: pharmacist, self medication, rational

\section{Pendahuluan}

Penggunaan obat rasional adalah pasien menerima obat yang sesuai dengan kebutuhan klinis, dalam dosis yang memenuhi kebutuhan individu, untuk jangka waktu yang memadai dan 
dengan biaya terendah bagi pasien maupun komunitas pasien (ASEAN Socio Cultural Community, 2017). Penggunaan obat yang tidak rasional sering di temui pada sistem perawatan kesehatan di seluruh dunia, khususnya di negara berkembang. Organisasi Kesehatan Dunia memperkirakan bahwa lebih dari setengah dari semua obat-obatan diresepkan, dibagikan, atau dijual secara tidak tepat dan setengah dari semua pasien gagal meminumnya dengan benar (Mamo \& Alemu, 2020). Penggunaan obat yang tidak rasional dapat berakibat pada hal yang tidak diharapkan, seperti; penurunan kualitas terapi yang dapat meningkatkan angka mortalitas dan mobilitas, berkurangnya ketersediaan obat yang disebabkan karena pengelolaan sumber daya obat yang tidak tepat dan meningkatnya biaya pengobatan (Indiarto et al., 2020).

Salah satu kegiatan pelayanan kefarmasian yang dilakukan oleh apoteker adalah konseling (Anonim, 2016). Kegiatan konseling yang dilakukan oleh apoteker dapat mengidentifikasi dan mengatasi masalah terkait obat, memberdayakan pasien untuk menerapkan manajemen perilaku diri yang positif, peningkatan kepuasan pasien dan dapat mengoptimalkan kualitas perawatan pasien. Konseling yang efektif akan membuat pasien mengerti tentang penyakit dan pengobatan yang sedang dijalani dan meningkatkan kepatuhan minum obat (Dewanti et al., 2015). Sebuah penelitian yang dilakukan oleh Satrio dkk menunjukkan bahwa terdapat perbedaan yang signifikan pada kelompok yang diberi pelayanan informasi obat dan konseling dibandingkan dengan kelompok tanpa pelayanan informasi obat dan konseling (Rahmatullah et al., 2020).

Berbagai masalah yang terkait dengan penggunaan obat masih banyak ditemui di masyarakat seperti kurangnya pengetahuan tentang penggunaan obat yang tidak rasional, penyalahgunaan obat, terjadinya efek samping obat, beredarnya obat palsu, narkoba dan bahan berbahaya lainnya, pengelolaan obat, penyimpanan obat, serta permasalahan kesehatan terkait dengan obat lainnya. Penyebab permasalahan tersebut adalah kurangnya kesadaran masyarakat akan arti pentingnya penggunaan dan pengelolaan obat yang baik. Sebuah penelitian menunjukkan bahwa pemberian edukasi tentang DAGUSIBU (dapat, gunakan, simpan, buang obat) dapat meningkatkan pengetahuan warga secara signifikan tentang penggunaan obat ( $\mathrm{p}=0,000)$ (Mukti \& Mayzika, 2020).

Hasil Riset Kesehatan Dasar (RISKESDAS) Tahun 2013 menyatakan bahwa terdapat $81,9 \%$ rumah tangga menyimpan obat keras dan $86,1 \%$ rumah tangga menyimpan antibiotika yang diperoleh tanpa resep dari dokter. Swamedikasi menggunakan obat keras dan obat antibiotika menunjukkan adanya penggunaan obat yang tidak rasional. Hal ini menunjukkan bahwa banyak masyarakat yang belum memahami tentang penggunaan obat yang rasional (Kurniasih et al., 2020). Metode yang bisa digunakan untuk memberikan edukasi kepada pasien dapat berupa; media cetak (booklet, leaflet, flyer, flip chart, rubrik, poster dan foto), media elektronik (televisi, radio, video, slide, dan film strip) dan media papan (bill board) (Muzakir, 2018). Sebuah penelitian menunjukkan bahwa sistem informasi obat buatan yang diimplementasikan dapat meningkatkan rasionalitas dan keterampilan masyarakat dalam melakukan swamedikasi (Suryono et al., 2019).

Pada penelitian sebelumnya dilakukan pembuatan aplikasi AKO (apoteker keluarga online) oleh dosen program studi sarjana Farmasi Universitas Muhammadiyah Lamongan sebagai media digital counseling karena banyak ditemukan perilaku swamedikasi dan DAGUSIBU yang kurang tepat sehingga pada kegiatan pengabdian masyarakat ini dilakukan sosialisasi penggunaan aplikasi tersebut agar aplikasi bisa dimanfaatkan oleh masyarakat dan dapat meningkatkan penggunaan obat yang rasional di masyarakat.

\section{Metode Pelaksanaan}

Pengabdian masyarakat ini dilaksanakan pada bulan November 2021 di Desa Bedingin Kecamatan Sugio Kabupaten Lamongan. Sasaran atau mitra dalam pengabdian masyarakat ini adalah kader desa Bedingin sejumlah 36 orang. Kegiatan pengabdian ini dilakukan dalam 4 tahapan sebagai berikut :

1. Identifikasi potensi dan masalah 
Identifikasi potensi dan masalah dilakukan dengan survei secara langsung ke lokasi mitra menggunakan metode pengamatan langsung dengan mengunjungi Desa Bedingin, wawancara mendalam kepada perwakilan desa, kepala desa serta bidan desa.

2. Penyusunan program Bersama masyarakat

Program bersama masyarakat disusun dari hasil identifikasi kebutuhan mitra dan potensi yang dimiliki oleh mitra. Pada tahap ini tim pengabdian berkoordinasi dengan perangkat desa untuk membuat jadwal kegiatan pengabdian sesuai kebutuhan mitra.

3. Edukasi Swamedikasi Rasional dan Sosialisasi aplikasi AKO (Apoteker Keluarga Online) sebagai media Konsultasi digital.

Pada tahap ini tim pengabdian memberikan materi tentang Swamedikasi yang Rasional dan konsep DAGUSIBU sebagai prinsip Kelola obat rumah tangga yang benar. Edukasi dilaksanakan dengan metode Focus Grup Discussion (FGD), evaluasi pemahaman masyarakat dilaksanakan dengan metode diskusi dan tanya jawab.

4. Pendampingan Penggunaan Obat yang Rasional dengan Media AKO

Tim pengabdian masyarakat memberikan pendampingan secara continue kepada masyarakat melalui aplikasi AKO yang dapat diunduh di PlayStore.

\section{Hasil dan Pembahasan}

Penduduk Indonesia telah terbiasa menggunakan bermacam jenis obat-obatan sebagai terapi terhadap penyakit, memelihara, ataupun sebagai vitamin dalam upaya menunjang kegiatan sehari-hari. Hal tersebut dapat terjadi oleh berbagai faktor misalnya perkembangan penyakit, produksi jenis obat-obatan dan suplemen serta mulai diberlakukannya jaminan kesehatan nasional yang memungkinkan masyarakat mendapatkan akses yang lebih mudah untuk mendapatkan pengobatan (Devi Ristian Octavia et al., 2020). Dengan banyaknya obat yang beredar secara bebas di masyarakat, maka diperlukan suatu pendekatan kepada masyarakat untuk meningkatkan awareness dan pengetahuan terhadap penggunaan obat yang rasional. Oleh karena itu, penyuluhan dalam rangka meningkatkan pengetahuan masyarakat terhadap hal tersebut sangatlah diperlukan (Kamaluddin et al., 2019). Salah satu penyebab masalah kesehatan yaitu penggunaan obat secara tidak rasional, yang dapat mengakibatkan terapi menjadi kurang efektif dan tidak efisien (Mutiara et al., 2021). Pemakaian obat disebut rasional apabila pasien mendapatkan obat yang tepat untuk kebutuhan klinis, dengan dosis yang sesuai kebutuhan dalam jangka waktu yang cukup, juga dengan biaya yang terjangkau baik untuk individu ataupun masyarakat (Devi Ristian; Octavia et al., 2019).

Pada Analisa awal ditemukan permasalahan yang dihadapi oleh masyarakat di desa Bedigin kecamatan Sugio kesulitan dalam akses informasi obat yang tepat. Hal tersebut disebabkan karena di desa Bedingin belum dijumpai Apotek, sehingga warga biasa mendapatkan obat-obatan dari tenaga Kesehatan lain, padahal apoteker adalah sumber informasi obat yang paling baik (Devi Ristian Octavia \& Utami, 2021). Sebagian besar masyarakat desa Bedingin Kecamatan Sugio belum memahami konsep pengobatan yang rasional. Pada pengabdian masyarakat yang telah dilakukan, masyarakat diberi edukasi tentang cara Kelola obat di rumah tangga dengan konsep DAGUSIBU (Dapatkan, Gunakan, Simpan dan Buang obat) dengan tepat. Dengan pengelolaan obat yang tepat selanjutnya diharapkan manfaat dari obat bisa optimal. Selain itu tim pengabdian juga menyampaikan tentang praktik swamedikasi rasional agar masyarakat terhindar dari bahaya pengobatan yang salah (Gambar 1). 

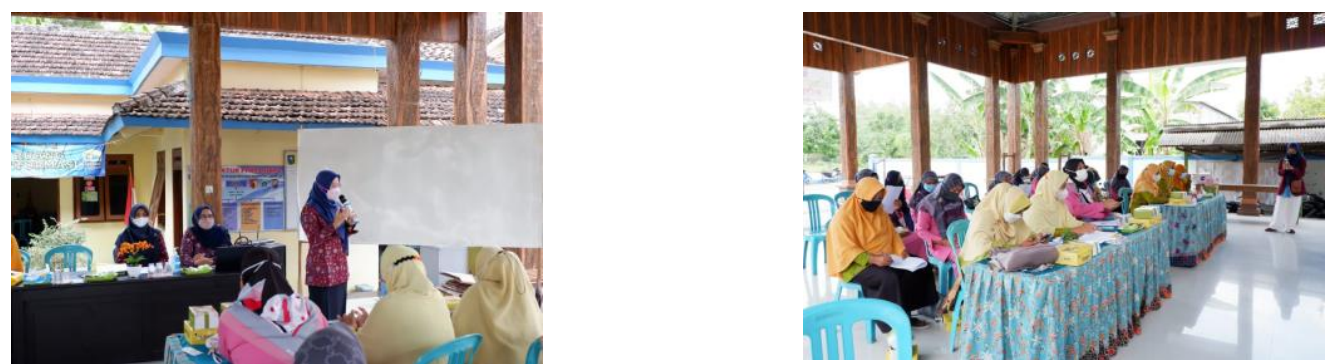

Gambar 1. Pemaparan materi tentang swamedikasi rasional

Pada tahap pemaparan materi dilaksanakan dengan metode cara belajar insan aktif (CBIA) di mana tim pengabdian menyampaikan materi kepada masyarakat dengan diskusi interaktif sehingga masyarakat dapat lebih memahami materi yang telah disampaikan. Masyarakat dipancing dengan beberapa pertanyaan mendasar misalnya, dari mana masyarakat mendapatkan obatnya selama ini, apakah informasi yang didapatkannya cukup, dan bagaimana masyarakat menyimpan serta memusnahkan obat yang sudah tidak terpakai. Ratnasari et al., (2019) mengungkapkan konsep DAGUSIBU obat yang benar dapat meminimalisir kesalahan dalam penggunaan obat. Hasil serupa juga dilaporkan bahwa metode CBIA dapat meningkatkan pengetahuan kader tentang DAGUSIBU (Djuria, 2018). Penyuluhan DAGUSIBU mampu meningkatkan pengetahuan yang signifikan masyarakat terhadap penggunaan obat yang benar (Devi Ristian Octavia et al., 2020).

Pengabdian masyarakat dilanjutkan dengan sosialisasi aplikasi AKO (Apoteker Keluarga Online) yang dapat diunduh dari aplikasi PlayStore pada smartphone dengan keyword AKO apoteker (Gambar 2).

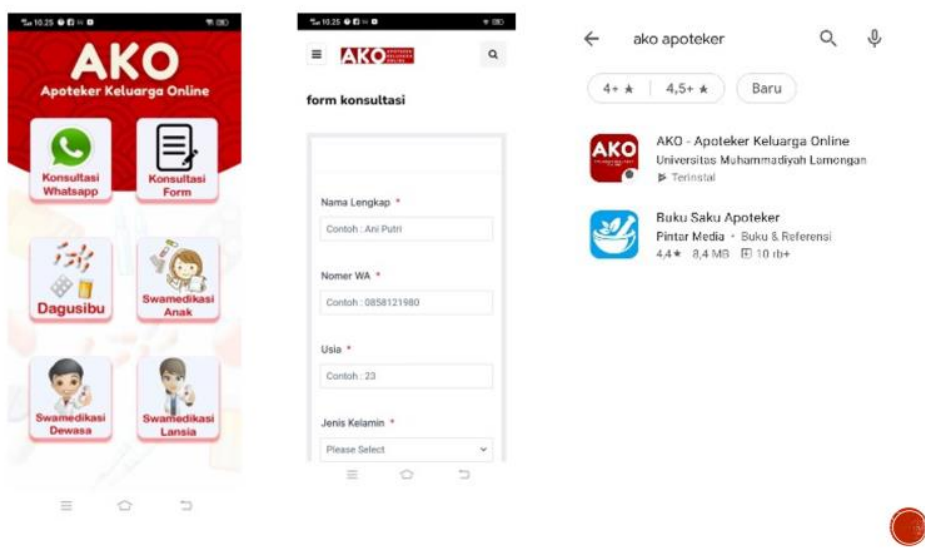

Gambar 2. Aplikasi AKO yang dapat diunduh dari PlayStore

Pada tahap pendampingan, tim pengabdian membentuk Apoteker Agent Of Change (AoC). Apoteker sebagai salah satu tenaga Kesehatan dapat berkontribusi secara signifikan dalam membantu program pemerintah dalam memberikan edukasi kepada masyarakat untuk berperilaku hidup sehat melalui penggunaan obat yang rasional (Adrianta et al., 2020). Pada tahap pendampingan ini, masyarakat dipersilahkan untuk melakukan konsultasi penggunaan obat mereka sehari-hari dengan memanfaatkan aplikasi AKO. Dalam aplikasi tersebut juga telah disediakan tutorial dalam praktik swamedikasi yang rasional untuk keluhan penyakit yang sering terjadi di masyarakat, misalnya demam, flu, batuk ataupun penyakit kulit.

Hasil pengabdian didapatkan masyarakat sangat antusias dalam memanfaatkan aplikasi tersebut untuk mengonsultasikan penggunaan obatnya. Konseling secara mendalam dapat dilanjutkan dengan mengisi form konsultasi ataupun via chatting yang akan langsung dijawab oleh tim Apoteker Agent of Change yang telah dibentuk.

Monitoring dan evaluasi dari keberhasilan program pengabdian ini adalah adanya perilaku penggunaan obat pasien yang dipantau melalui digital counselling di mana $67 \%$ mitra mengalami peningkatan pengetahuan tentang penggunaan obat yang rasional. 


\section{Simpulan}

Edukasi swamedikasi rasional dan pendampingan konsultasi penggunaan obat menggunakan aplikasi AKO mampu meningkatkan pengetahuan masyarakat tentang penggunaan obat yang rasional.

\section{Daftar Pustaka}

Adrianta, K. A., Meriyani, H., \& ... (2020). Pendidikan Pola Hidup Sehat Dan Penggunaan Obat Yang Rasional Sejak Dini Untuk Meningkatkan Derajat Kesehatan Masyarakat. Jurnal Aplikasi Dan ..., 2(1), 8-14. https://jasintek.denpasarinstitute.com/index.php/jasintek/article/view/42

Anonim. (2016). Peraturan Menteri Kesehatan Republik Indonesia Nomor 73 Tahun 2016. $14-16$.

ASEAN Socio Cultural Community. (2017). Rational Use of Medicines in the Asean Region. ASEAN Secretariat.

Dewanti, S. W., Andrajati, R., \& Supardi, S. (2015). Pengaruh Konseling dan Leaflet terhadap Efikasi Diri, Kepatuhan Minum Obat, dan Tekanan Darah Pasien Hipertensi di Dua Puskesmas Kota Depok. Jurnal Kefarmasian Indonesia, 5(1), 33-40. https://doi.org/10.22435/jki.v5i1.4088.33-40

Djuria, R. F. (2018). Peningkatan Pengetahuan Tentang Dagusibu Terhadap Kader Gerakan Keluarga Sadar Obat ( Gkso ) Desa Tanjung Gunung Bangka Tengah Increased Knowledge About Dagusibu To Cadres Conscious Family Medicine ( Gkso ) in Tanjung Gunung Village Central Bangka Regency. Jurnal Kesehatan Poltekkes Pangkalpinang, $6(1)$.

Indiarto, E. N., Herawati, F., Wardani, S. A., Farmasi, F., Surabaya, U., Presiden, B. P., Nasional, S. K., No, P., Sidoarjo, P. K., Penggunaan, P., Rasional, O., Sidoarjo, P. K., Nasional, P. O. R., Sidoarjo, P. K., Gedangan, P., Gedangan, P., Kunci, K., Rasional, P. O., \& Nasional, F. (2020). Profil Penggunaan Obat Rasional di Puskesmas Kabupaten Sidoarjo Provinsi Jawa Timur Tahun 2017. 9(September).

Kamaluddin, M. T., Tamzil, N. S., Lusiana, E., Farmakologi, B., Kedokteran, F., Sriwijaya, U., Pendahuluan, I., \& Palembang, S. B. (2019). Penggunaan Obat RasionalSwamedikasi Pada Kader. 7(2), 742-744.

Kurniasih, K. A., Supriani, S., \& Yuliastuti, D. (2020). Analisis Faktor Tingkat Pengetahuan Masyarakat Tentang Tindakan Swamedikasi Diare. Media Informasi, 15(2), 101-105. https://doi.org/10.37160/bmi.v15i2.321

Mamo, D. B., \& Alemu, B. K. (2020). Rational drug-use evaluation based on world health organization core drug-use indicators in a Tertiary Referral Hospital, Northeast Ethiopia: A cross-sectional study. Drug, Healthcare and Patient Safety, 12, 15-21. https://doi.org/10.2147/DHPS.S237021

Mukti, A. W., \& Mayzika, N. A. (2020). Profil Perilaku dan Pengetahuan Warga Kelurahan Dukuh Menanggal Surabaya tentang DAGUSIBU. Dedication : Jurnal Pengabdian Masyarakat, 4(1), 1-10. https://doi.org/10.31537/dedication.v4i1.294

Mutiara, J. A., Handini, M. C., Ketaren, S. O., Dakhi, R. A., Pascasarjana, D., Sari, U., \& Indonesia, M. (2021). Penggunaan obat rasional melalui edukasi gema cermat dengan metode cbia. 2(September), 209-216.

Muzakir, A. (2018). Prototyping Aplikasi E-Health sebagai Bagian Pengenalan Obat-Obatan 
Dengan Teknologi Cross-Platform. 03(01), 61-66.

Octavia, Devi Ristian; Zakaria, M. S., \& Nurafifah, D. (2019). Tingkat Pengetahuan Masyarakat Tentang Swamedikasi yang Rasional di Lamongan. Surya, 11(02), 10-16.

Octavia, Devi Ristian, Susanti, I., Bintang, S., Mahaputra, S., Negara, K., Kesehatan, F. I., \& Lamongan, U. M. (2020). PENINGKATAN PENGETAHUAN MASYARAKAT TENTANG PENGGUNAAN DAN PENGELOLAAN OBAT YANG RASIONAL MELALUI PENYULUHAN DAGUSIBU. GEMASSIKA, 4(1), 23-39.

Octavia, Devi Ristian, \& Utami, P. R. (2021). The Relationship between Knowledge and Attitudes and the Rationality of Antibiotic Use Behavior in Pharmacy Students. 10(1), 783-792. https://doi.org/10.30994/sjik.v10i1.713

Rahmatullah, S. W., Nurrahma, I. M., \& Syahrizal, A. (2020). Pengaruh Pemberian Pelayanan Informasi Obat Dan Konseling Terhadap Tingkat Kepatuhan Minum Obat Pada Pasien Diabetes Melitus Dengan Hipertensi Di Rumah Sakit Daerah Idaman Banjarbaru. Jurnal Ilmiah Ibnu Sina (JIIS) Ilmu Farmasi Dan Kesehatan, 5(2), 240-249. https://doi.org/10.36387/jiis.v5i2.462

Ratnasari, D., Norainny, Y., \& Pemta, T. D. (2019). Penyuluhan Dapatkan -Gunakan Simpan -Buang (DAGUSIBU) Obat. Jcee, 1(2), 55-61.

Suryono, R. R., Nurhuda, Y. A., \& Ridwan, M. (2019). Analisis Perilaku Pengguna Sistem Informasi Pengetahuan Obat Buatan Untuk Kebutuhan Swamedikasi. Jurnal Teknoinfo, 13(1), 1. https://doi.org/10.33365/jti.v13i1.134 